\title{
Editorial
}

\section{Cultura e desenvolvimento: 100 anos de Celso Furtado, um intelectual cosmopolita}

Editor Convidado:

João Antonio de Paula (1)

(1) Universidade Federal de Minas Gerais/Cedeplar

\section{Elementos de biografia e bibliografia}

Celso Furtado ocupa lugar especial entre os grandes intelectuais brasileiros do século XX. Entre pensadores que nada ficam a dever a seus pares estrangeiros, como Sérgio Buarque de Holanda, Florestan Fernandes, Antonio Candido, Celso Furtado destacou-se, seja por sua rica experiência, no Brasil, como servidor público, seja por sua experiência internacional, como funcionário das Nações Unidas, seja como professor, seja por sua obra, que, fincada na economia, abarcou diversas dimensões das humanidades, a saber: a história, a sociologia, a ciência política, a filosofia, a literatura, as artes.

Celso Furtado (1920-2004), paraibano da cidade de Pombal, filho de família de classe média letrada, esteve, desde cedo, exposto ao vasto mundo da cultura erudita. Seu pai, juiz de direito, tinha considerável biblioteca, que Celso Furtado frequentou com assiduidade e interesse. Depois de estudar em João Pessoa, transferiu-se para Recife onde concluiu seu curso médio. Em 1940, mudou-se para o Rio de Janeiro, onde vai estudar Direito, bacharelando-se, em 1944, pela Faculdade de Direito da Universidade do Brasil, atual Universidade Federal do Rio de Janeiro (UFRJ). Durante o curso, para ajudar a custear sua estadia no Rio, passou a escrever para a Revista da Semana e para o jornal Correio da Manhã, como revisor. Ao lado das atividades na Faculdade e as jornalísticas, Celso Furtado vai ter oportunidade de explorar, ainda mais, sua forte paixão pela música, estudar piano na Paraíba, e no Rio de Janeiro vai se tornar um permanente e entusiasmado frequentador do Teatro Municipal e de outras salas de concerto. Estudou 
inglês com afinco, ao mesmo tempo que desenvolveu impressionante esforço de leitura, que abrangeu da filosofia à literatura brasileira e estrangeira, confirmou sua paixão pela história e descobriu a economia. Em 1945, foi aprovado no concurso para trabalhar, como técnico de organização e administração, no Departamento de Administração do Serviço Público (DASP), que, à época, era o órgão do governo federal mais próximo de atividades que mais tarde estarão afeitas ao Ministério do Planejamento. Em fevereiro de 1945, alistado na Força Expedicionária Brasileira (FEB) e com o posto de tenente, embarcou para a Itália para lutar na guerra, retornando ao Brasil em setembro de 1945.

Suas experiências na guerra foram narradas em livro, publicado em 1946, De Nápoles a Paris. Contos da vida expedicionária. Também em 1946, leu, com interesse, O capital, de Marx, e Economia e sociedade, de Max Weber, retomou seus estudos do idioma alemão e continuou suas atividades profissionais no DASP. Em 1947, voltou à Europa, para Paris, para curso de doutorado em Economia, concluído em 1948, com a tese Economia colonial no Brasil nos séculos XVI e XVII, que só foi publicada no Brasil, em 2001, por instâncias do professor Tamás Szmrecsányi, então presidente da Associação Brasileira de Pesquisadores em História Econômica (ABPHE). Sua estadia em Paris foi mais que frutuosa pela oportunidade que teve de assistir a cursos de grandes nomes do pensamento marxista, como Jean Baby e Auguste Cornu; com historiadores da política, como Jean-Jacques Chevallier, tomando contato direto com a École des Annales, aluno que foi de Charles Morazé. Frequentou cursos regulares de doutorado em Economia, na Sorbonne, e disciplinas isoladas no Institut d'Études Politiques, que lhe garantiram sólida formação em economia política, história econômica, economia social comparada e estatística econômica. Voltou ao Brasil em 1948. Em fevereiro de 1949, passou a fazer parte da equipe inaugural da Comissão Econômica para a América Latina e Caribe (Cepal), órgão das Nações Unidas, instalado em Santiago do Chile, liderada pelo economista argentino, Raul Prébisch, voltado para o estudo da realidade econômica e social da região.

Participou, como efetivo formulador, do que vai se constituir como Economia Política Latino-americana. Em 1953, de volta ao Brasil, dirigiu o grupo misto Cepal/BNDE, que vai elaborar sistemática pesquisa sobre as condições de possibilidade da industrialização brasileira, que resultou no Plano de Metas, lançado no governo Juscelino Kubitscheck, e que teve 
decisivo papel na aceleração industrial brasileira, entre outras medidas modernizantes, sintonizadas ao objetivo-síntese - o desenvolvimento nacional.

Entre 1953 e 1958, Celso Furtado tornou-se um dos nomes-chave do "pensamento desenvolvimentista", que reuniu, além dos membros do grupo Cepal/BNDE, o Instituto Superior de Estudos Brasileiros (ISEB), órgão ligado ao Ministério da Educação, que funcionou, entre 1955 e 1964, núcleo formulador da política e da ideologia desenvolvimentista no Brasil. Durante esse período, 1953 e 1958, Celso Furtado deu início à publicação de uma obra que se fez vasta e diversa em suas temáticas e perspectivas, sem deixar de ser, mesmo quando falando dos "ares do mundo", uma permanente interrogação sobre o Brasil, sua formação econômico-social, seus atavismos e condicionamentos, suas crônicas mazelas, mas, também, sobre suas possibilidades emancipatórias.

Seu primeiro livro, Economia brasileira, é de 1954; em 1956, publicou Uma economia dependente; em 1958, Perspectivas da economia brasileira, que saiu pelo ISEB, resultado de conferências que proferiu na instituição, em 1957. Nesse mesmo ano, desligou-se da Cepal e foi para a Inglaterra, para a Universidade de Cambridge, onde, entre 1958 e 1959, aprofundou seus conhecimentos sobre o pensamento keynesiano com um grupo que reunia Nicholas Kaldor, Joan Robinson, Luigi Pasinetti, responsável pela renovação da macroeconomia keynesiana em perspectiva progressista. Durante sua permanência em Cambridge escreveu seu livro mais conhecido, sua primeira obra-prima, Formação econômica do Brasil, publicado em 1959. De volta ao Brasil, em 1959, deparou-se com fenômeno recorrente, que infelicitava o semiárido brasileiro secularmente, a seca. Em 1957, a seca afetava meio milhão de pessoas no Nordeste brasileiro. Convocado pelo presidente da República elaborou, em tempo recorde, um documento da Operação Nordeste - "Uma política de desenvolvimento econômico para o Nordeste", com diagnóstico e propostas de enfrentamento estratégico das crônicas desigualdades que, historicamente, se impuseram à sociedade nordestina.

Atender à convocação presidencial, mais que um gesto profissional, foi um reencontro. Nascido no sertão da Paraíba, em época ainda de forte mandonismo, de coronelismo - e não mudou muito desde então -, Celso Furtado viveu no ambiente marcado pelas correrias do capitão Virgulino, pelo protetorado messiânico-político do Padre Cícero, pelas iníquas condições de vida impostas ao campesinato e ao lumpesinato urbano, assom- 
brados pela fome, pela miséria, resultantes não exatamente da seca, mas da cerca, do latifúndio, da concentração da renda, da riqueza, do poder e da informação. De fato, os efeitos da seca no nordeste brasileiro são amplificados pela vigência de exacerbada concentração da terra e dos meios de vida. Para efeitos de comparação, lembre-se que as chuvas são mais escassas na meseta espanhola, que no Nordeste brasileiro.

Em 15 de dezembro de 1959 foi sancionada a lei que criou a Superintendência de Desenvolvimento do Nordeste (Sudene). Em 8 de janeiro de 1960, Celso Furtado tomou posse como primeiro superintendente do órgão, que vai dirigir, com interrupção para ocupar cargo de Ministro do Planejamento do Governo João Goulart, entre 1962 e 1963, até 1964.

$\mathrm{Na}$ Sudene, Celso Furtado testou os limites da racionalidade planejadora, diante dos constrangimentos político-sociais postos pelos donos da terra, do dinheiro e do poder, tendo que enfrentar as oligarquias latifundiárias e seus acólitos. Celso Furtado viveu a dramática experiência de tentar reformas, sem qualquer radicalismo, em estruturas cristalizadas por séculos de exclusão, escravidão, opressão e completamente contrárias a qualquer mudança, que retire qualquer um dos privilégios que usufruíram na colônia, no Império e na República.

Com todas as cautelas, evitando provocações, Celso Furtado navegou águas turbulentas, evitando naufragar um amplo movimento de reformas, que, desde 1955, com as Ligas Camponesas, vinha lutando pela Reforma Agrária no Brasil. Celso Furtado, seja à frente da Sudene, seja como Ministro de Planejamento, foi decisivo nome da luta pelas reformas estruturais no Brasil, chamadas de Reformas de Base, que compuseram o Plano Trienal de Desenvolvimento Econômico e Social (1963-1965), elaborado por Celso Furtado em 1962, e que teve curtíssima vigência, atropelado pela agudização da crise política, que vai levar ao golpe de 1964.

Em Celso Furtado, a permanente busca de compreensão do Brasil foi sempre acompanhada do igualmente indescartável compromisso com a transformação do País mediante reformas estruturais distributivas, includentes, democráticas e populares. Esse esforço está registrado numa série de livros publicados entre 1962 e 1968, a saber: A pré-revolução brasileira, 1962; Dialética do desenvolvimento, de 1964; Subdesenvolvimento e estagnação na América Latina, 1966; Um projeto para o Brasil, 1968. Entre livros, há expressiva mudança de tom, dos tons luminosos e esperançosos, que correspondem aos tempos de certo otimismo nas possibilidades das reformas, 
entre 1962 e 1964, aos tons sombrios do pós-1964, presente em Subdesenvolvimento e estagnação na América Latina; e de novo a luz, a confiança, a retomada da potência crítica, com as explosões de 1968, refletidas em Um projeto para o Brasil. O balanço dessa experiência está registrado no como livro de 1992, Brasil, a construção interrompida, que sendo o relato de uma derrota sabe que ela não é definitiva.

Falou-se aqui da presença constante do Brasil no pensamento de Celso Furtado, lembrou-se de que tal busca do País, também, sempre foi a busca de maneiras de transformá-lo, de fazê-lo solidário, democrático, popular, que constitui o segundo núcleo da obra de Celso Furtado, o das reformas estruturais. Um terceiro núcleo, o teórico, isto é, a construção de uma teoria do desenvolvimento e do subdesenvolvimento, acabou por amalgamar todas as dimensões da reflexão furtadiana. Com efeito, na obra de Celso Furtado o conceito de "desenvolvimento" e sua contraparte, o conceito de "subdesenvolvimento", tem função heurística assemelhada ao conceito de "tipo ideal" weberiano. Construtos teóricos, desenvolvimento e subdesenvolvimento são referências categoriais que permitem aferir, por cotejamento, as diferenças histórico-concretas entre as realidades sociais específicas e o desenvolvimento e o subdesenvolvimento, considerados como tipos ideais. Nessa operação teórico-metodológica a primeira providência foi a complexificação do conceito de desenvolvimento, retirando-o do leito estreito em que o pensamento econômico convencional o tinha confinado, ao igualar desenvolvimento a crescimento econômico.

Em vários momentos de sua obra e em grau crescente de complexidade, Celso Furtado foi construindo o conceito de desenvolvimento como transformação estrutural de relações econômicas, políticas, sociais, culturais e tecnológicas sintonizadas à melhoria da qualidade de vida do conjunto da população, à universalização de direitos sociais básicos, à sustentabilidade.

O caminho da construção da teoria do desenvolvimento e do subdesenvolvimento teve início em 1961, com a publicação de Desenvolvimento e subdesenvolvimento. Em 1967, o livro de 1961 foi ampliado e refundido em movimento que buscou explicitar sua forte reivindicação teórica, sua intenção de ser contraponto efetivo ao que o mainstream do pensamento econômico vinha construindo sobre "crescimento econômico", mediante a elaboração de uma "economia política do desenvolvimento econômico" que é objetivo de Teoria e política do desenvolvimento econômico. Em 1974 e 1975, o conceito de desenvolvimento econômico que Celso Furtado estava 
construindo foi enriquecido com a publicação de $O$ mito do desenvolvimento econômico e com a redação do curso ministrado na PUC-SP, Economia do desenvolvimento, somente publicado em 2008. Nesse livro a teoria do desenvolvimento é enriquecida pela incorporação de duas questões que vão impactar, fortemente, o conjunto da economia capitalista e, em particular, as economias periféricas, a saber: de um lado, a crise estrutural do capitalismo, que começou a se manifestar no início dos anos de 1970, encerrando a longa expansão iniciada pós-1945; e de outro lado, a transnacionalização do capitalismo, ponto de partida para a "globalização globalitária", como a chamou Milton Santos, que vai se impor a partir da década de 1990. Incapaz de cultivar ilusões, Celso Furtado reconheceu que a ideia-força-programa representada pelo desenvolvimento poderia ser transformada em mito, conveniente para a dominação capitalista. Diz ele:

\begin{abstract}
Sabemos agora de forma irrefutável que as economias da periferia nunca serão desenvolvidas, no sentido de similares às economias que formam o atual centro do sistema capitalista. Mas como negar que essa ideia tem sido de grande utilidade para mobilizar os povos da periferia e levá-los a aceitar enormes sacrifícios, para legitimar a destruição de formas de cultura arcaicas, para explicar e fazer compreender a necessidade de destruir o meio físico, para justificar formas de dependência que reforçam o caráter predatório do sistema produtivo? (Furtado, 1983, p. 75).
\end{abstract}

O quarto núcleo temático da obra de Celso Furtado é o referente às relações de dominação externa. Sem ter usado, explicitamente, o conceito de imperialismo, é disso que se trata quando Furtado aborda as relações entre os países periféricos e a hegemonia do grande capital, em particular do capitalismo norte-americano. É sintomático que o último livro a ser publicado por Celso Furtado, em 2003, um ano antes de morrer, seja Raízes do subdesenvolvimento, que é retomado do livro publicado em 1973, A hegemonia dos Estados Unidos e o subdesenvolvimento da América Latina. Em 1987, Celso Furtado publicou Transformação e crise na economia mundial, em que sistematizou sua visão sobre o "subdesenvolvimento como uma formação socioeconômica engendrada pelo sistema de divisão internacional do trabalho" (Furtado, 1987, p. 9).

Economista, obrigado por força de constrangimentos políticos, exposto aos "ares do mundo", Celso Furtado se fez cosmopolita em variadas atividades profissionais e intelectuais em diversos países da América Latina, Estados Unidos, Europa, Ásia, África. Sobre a América Latina deixou contribuição considerável sob a forma de dois livros: Formação econômica da América Latina, publicado, inicialmente, em 1969, reescrito em 1976, 
e que desde então recebeu o título de A economia latino-americana. Outro texto importante de Celso Furtado, sobre a América Latina, é Ensaios sobre a Venezuela, que reúne trabalhos escritos sobre aquele país, em 1957 e 1974, analisando as consequências, sobre economias subdesenvolvidas, da abundância de divisas decorrentes da exportação de petróleo, tema que só ganhou atualidade ao longo do tempo.

No final dos anos de 1960 a economia brasileira experimentou forte crescimento econômico, resultado de circunstâncias e determinações em nada triviais, a saber: forte arrocho salarial e repressão ao movimento sindical; reformas tributária, financeira e administrativa, que modernizaram o sistema financeiro, estimularam a poupança pública e privada e viabilizaram o sistema financeiro de habitação, entrada maciça de capitais estrangeiros.

Depois da recessão que se abateu sobre a economia brasileira, entre 1961 e 1967, a política econômica da ditadura começou a dar expressivos resultados em termos de crescimento do Produto Interno Bruto (PIB) que, entre 1969 e 1973, cresceu a uma taxa média de 11\% ao ano. Viu-se nisso fenômeno equivalente ao crescimento, que marcou as economias de Alemanha, Japão e Itália, pós-1945, chamadas "milagrosas". Para Celso Furtado, mais importante que buscar mostrar o equívoco da identificação entre o "milagre" brasileiro e aqueles outros "milagres" ocorridos em países centrais foi a firme disposição crítica de que se armou para combater as consequências negativas sobre os trabalhadores e outros setores populares decorrentes da política da ditadura, seja em sua fase "milagrosa", seja em sua fase de crise, que se instalou na segunda metade dos anos de 1970 e se prolongou até o final da ditadura, em 1985. Fazem parte desse núcleo da obra de Celso Furtado, voltada para o combate à política econômica da ditadura, os livros: Análise do "Modelo" Brasileiro, de 1972; O Brasil Pós-"Milagre", de 1981; A nova dependência (dívida externa e monetarismo), de 1982; Não à recessão e ao desemprego, de 1983.

Em 1984, Celso Furtado recuperou seus direitos políticos e, de volta ao Brasil, passou a desenvolver atividades políticas no Partido do Movimento Democrático Brasileiro (PMDB), na movimentação que envolveu a Campanha pelas Eleições Diretas e a Eleição pelo Colégio Eleitoral. Os eleitos no Colégio Eleitoral, em 1985, não convidaram Celso Furtado para ocupar cargos na área econômica do governo, funções para as quais ele não só estava perfeitamente preparado para ocupar, quanto traria para elas seu indeclinável compromisso crítico e criativo. Escolhido para representar o 
Brasil na Comunidade Europeia, Celso Furtado voltou ao Brasil, em 1985, para ocupar o Ministério da Cultura, onde mostrou, mais uma vez, seu notável preparo intelectual e sua capacidade administrativa.

Ainda que não estivesse em seus planos, ou desejos, ser Ministro da Cultura, ocupou com entusiasmo o cargo que lhe permitia, de um lado, contribuir para a complexa tarefa de redemocratização do país, depois de 21 anos de ditadura, e, de outro lado, ocupar-se de questão que sempre o mobilizara. Vocação precoce despertada pelos estímulos familiares e genuíno interesse intelectual, Celso Furtado descobriu cedo sua paixão pela história e pela literatura. Seus diários, publicados em 2019, dão conta de dois objetivos aos quais vai aplicar o melhor de seu esforço intelectual, ao longo de sua vida: escrever literatura ficcional relevante e elaborar interpretação do Brasil de excelência. Mais de uma vez tentou escrever um grande romance, que acabou não sendo escrito. No campo da ficção publicou apenas um livro de contos, seu primeiro livro. Já no referente à interpretação do Brasil sua obra destaca-se entre as grandes.

Por dever de ofício instado a pensar a cultura brasileira, Celso Furtado não se fez de rogado e não só elaborou instigantes teses sobre o desenvolvimento cultural brasileiro e suas relações com o desenvolvimento econômico do país, quanto desenvolveu legislação, políticas e ações que consolidaram o Ministério da Cultura. Um registro de atuação de Celso Furtado no Ministério da Cultura está no volume organizado por Rosa Freire d'Aguiar Furtado, Ensaios sobre cultura e o Ministério da Cultura, publicado em 2012. Em 1984, Celso Furtado publicou Cultura e desenvolvimento em época de crise, em que, explicitamente, discutiu as relações entre desenvolvimento e cultura (Furtado, 1984).

Registre-se um último núcleo temático da obra de Celso Furtado, o autobiográfico, que inclui: os três volumes de autobiografia - A fantasia organizada; A fantasia desfeita, os ares do mundo - republicada, em 2014, em volume único, com o título Obra autobiográfica; e Diários intermitentes (19372002), publicado em 2019.

\section{Celso Furtado, intelectual cosmopolita}

Vários intelectuais brasileiros produziram obras e intervenções no debate cultural em que se ombrearam aos grandes nomes internacionalmen- 
te reconhecidos; pesou contra eles o idioma que usaram, escassamente conhecido em âmbito internacional. Quando escreveram em língua estrangeira, como José Guilherme Merquior, em L'esthétique de Lévi-Strauss (Merquior, 1977), tiveram a aprovação da "república internacional das letras". Quando obras superlativamente qualificadas, por exemplo, Visão do paraíso, de Sérgio Buarque de Holanda (Holanda, 1969), livro de erudição, sofisticação estilística e finura de análise raríssimas, ficam confinadas ao nosso belo e desconhecido idioma é como se não existissem. É ainda de Sérgio Buarque de Holanda outro exemplo de imerecida invisibilidade, resultante do idioma em que foi escrito, e que condena ao desconhecimento um estudo - $O$ atual e o inatual na obra de Leopold Von Ranke (Holanda, 1974) - que enriqueceria a muitas vezes rica historiografia alemã. Tomem-se outros exemplos. O livro de Florestan Fernandes, Fundamentos empíricos de explicação sociológica, não é inferior a celebradas obras de autores norte-americanos, como Talcott Parsons e Robert Merton, sobre os fundamentos teóricos e metodológicos da sociologia funcionalista. Se publicado em idioma de circulação internacional, o livro Crítica e resignação, de Gabriel Cohn (Cohn, 1979), sobre a obra de Max Weber, estaria entre as referências indispensáveis para compreensão mais acurada daquele autor. Interrompa-se a enumeração que levaria a indesculpáveis omissões.

O que se quer sublinhar é que Celso Furtado, desde muito cedo, descobriu que tinha algo importante a dizer sobre o mundo, e que, para isso, ele teria de se fazer um intelectual público. Essa descoberta de alguma coisa nele que o impulsionava para a vida pública, para a vida intelectual, para a publicização de ideias que teimavam em buscar um público amplo, o debate, foi se confirmando pelo esforço sistemático dos estudos, da reflexão, da invenção, que a cada momento deram-lhe mais segurança, mais coragem de expor, de debater, de confrontar ideias, em variados ambientes, com diversos interlocutores, com altivez, sem subalternidade, permitindo-se os mesmos amplos voos do espírito, que parecem monopólio dos intelectuais dos países centrais.

Celso Furtado tem carreira profissional, em grande medida, no exterior, com passagens, como docente, na Universidade de Colúmbia, na Universidade de Yale, na Sorbonne, além de períodos de estudos em Cambridge, ao que se deve agregar sua participação em organizações internacionais, que exigiram permanente intercâmbio em variados países. 
Essas circunstâncias biográficas fizeram de Celso Furtado o intelectual brasileiro mais internacional, excluídos desse rol os intelectuais, que exerceram cargos diplomáticos.

Mas, não é exatamente esse sentido de internacionalização que se quer realçar em Celso Furtado, mas o caráter cosmopolita de sua obra. Mesmo quando tratando de temas nacionais, a formação econômica do Brasil, por exemplo, Celso Furtado aborda-o de modo que o essencial do que está sendo investigado seja compreensível em qualquer lugar, por se concentrar nos aspectos estruturais das questões analisadas, evitando a folclorização da narrativa, que fez o sucesso internacional de outros autores brasileiros, como Gilberto Freyre. Escritor avesso ao abuso de hipérboles e maneirismos, Celso Furtado é da família dos autores medulares como Graciliano Ramos, como João Cabral de Melo Neto, avesso à adiposidade da escrita preciosa.

Mas, ainda não é essa a característica que se quer destacar da obra de Furtado. Para esclarecer o ponto, e mostrar o que se sustenta aqui, Celso Furtado como intelectual cosmopolita, examinem-se dois livros: Prefácio à nova economia política (Furtado, 1976) e Criatividade e dependência na civilização industrial, publicado em 1979 (Furtado, 2008).

Prefácio à nova economia política, o autor o declara, é o resultado de um quarto de século de tateios nos "labirintos das teorias econômicas e esforçando-me para descobrir relações entre os ensinamentos que daí derivam e os problemas práticos de nossa época, convencendo-me sobejamente da insuficiência do quadro conceitual com que se trabalha nessa ciência." (...) "minha intenção é chamar a atenção para a situação atual de carência de uma teoria geral das formações sociais, que sirva de ponto de partida para o estudo dos problemas particulares que preocupam os economistas." (...) trata-se, enfim, da "busca de uma teoria social e global, na qual entronquem a teoria da reprodução das populações, a teoria das decisões intertemporais (acumulação), a teoria da estratificação social e a teoria do poder (Furtado, 1976, pp. 9-11).

Por duas vezes Celso Furtado esteve na Universidade de Cambridge, entre 1958-1959, e entre 1973-1974, em momentos-chave do debate entre nomes proeminentes do pensamento neoclássico - Samuelson, Solow Meade - e do pensamento keynesiano e neorricardiano - Joan Robinson, Nicolas Kaldor, Luigi Pasinetti e Piero Sraffa. Na década de 1950, houve importante debate sobre a teoria do crescimento econômico, tendo como 
pontos de controvérsias os modelos de crescimento econômico inspirados na teoria neoclássica, associados aos nomes de Harrod, Domar e Solow, e as críticas a esses modelos formulados por autores keynesianos, já mencionados. Celso Furtado esteve em Cambridge no auge desse debate, aprendendo com ele, mas, desde sempre, cônscio de que mesmo em sua versão cambridgeana, a questão da "dinâmica econômica", tal como entendida naquele contexto, era incapaz de dar conta do essencial do que importava apreender. Diz Furtado:

\begin{abstract}
A matéria com que se preocupa o economista são determinados problemas sociais que foram simplificados expressamente para poderem ser tratados com certos métodos. Esse processo de simplificação assume, via de regra, a forma de eliminação do fator tempo. O erro metodológico da chamada "dinâmica econômica" consiste exatamente em pretender reintroduzir o fator tempo mantendo os problemas com o mesmo grau de simplificação, como se o tempo existisse em si mesmo, independentemente de qualquer conteúdo. Dinamizar significa, necessariamente, tornar os problemas mais espessos, mais complexos, portanto desbordar os limites do "econômico". O avanço na direção de uma dinâmica econômica passa por uma compreensão dos processos sociais globais, ou seja, pela construção de um quadro teórico que permita abordar o estudo do conjunto dos processos sociais (Furtado, 1976, p. 11).
\end{abstract}

Esse esforço de reconstrução teórica proposto por Celso Furtado não significa buscar o que ele chamou de enfoque "interdisciplinário", mas de efetiva busca de "teoria social global". O roteiro dessa busca ele esboçou no Prefácio à nova economia política e na Tábua da matéria sugerida que o acompanha.

Levar a sério o fator tempo, para Celso Furtado, não significa tomá-lo como um continuum reversível, que pode ser trilhado para frente $-1,2,3$, $4, \ldots$, ou para trás - ...4, 3, 2, 1 -, mas reconhecê-lo como realidade, inerentemente irreversível e entrópica, aberta e não teleológica. Essa concepção de um tempo espesso é o fundamento de uma concepção de história, igualmente espessa, que é central no pensamento de Celso Furtado. Com efeito, o Prefácio elaborado por Celso Furtado é uma tentativa de construir uma visão global de estruturas historicamente dadas, de formações sociais concretas (Furtado, 1976, p. 11).

O Prefácio e a Tábua da matéria retrilham o caminho da economia política, de sua gênese, com os clássicos até os seus desdobramentos no século $\mathrm{XX}$, com as contribuições keynesianas; schumpterianas, institucionalistas, neorricardianas e ecologistas. Parte-se do todo, das formas históricas concretas de organização social, da centralidade da produção, para depois considerar a geração do excedente, a distribuição da renda, os conflitos distributivos e a luta de classes, a acumulação de capital e a inovação tec- 
nológica, as relações econômicas internacionais, o Estado e a coordenação das atividades socioeconômicas, a entropia e a desorganização dos ecossistemas, o processo de urbanização e as possibilidades do desenvolvimento econômico no mundo contemporâneo. Escritos em 1976, o Prefácio e a Tábua enfatizam questões que, à época, não tinham a visibilidade que desfrutam hoje.

A Nova Economia Política que Celso Furtado prefaciou conservou de suas origens o melhor: a centralidade da produção; o protagonismo das classes sociais; a geração e a luta pelo excludente; a divisão do trabalho e o progresso tecnológico; o Estado e as relações econômicas internacionais; a população e as relações de propriedade; a renda e a riqueza; as crises e a acumulação de capital. Trata-se de universo teórico que, de fato, mobiliza o conjunto das chamadas ciências sociais: a economia, a sociologia, a demografia, a ciência política, o direito, a geografia. Foi assim que a Economia Política surgiu, foi essa a pauta temática Economia Política Clássica , do final do século XVII ao início do século XIX, de William Petty e Pierre Boisguillebert a Ricardo e Sismondi (Marx, 1974).

Com o pensamento neoclássico houve o abandono desse fundamental patrimônio teórico. Celso Furtado insistiu na necessidade de se retomar, de se atualizar a economia política, mediante esforço que envolveria tanto a valorização do grande legado clássico, como o fez Piero Sraffa, quanto a incorporação da crítica da economia política tal como Marx a formulou, quanto a mobilização de outras vertentes do pensamento como o historicismo, o institucionalismo, os desdobramentos contemporâneos do pensamento econômico.

Tendo assistido in loco, isto é, em Cambridge, ao auge do debate sobre valor e distribuição entre neoclássicos versus neokeynesianos e neorricardianos, nos anos de 1960/1970, Celso Furtado incorporou a contribuição sraffiana num sentido muito mais amplo que a maioria dos sraffianos. Para Celso Furtado, a demolidora crítica de Sraffa ao paradigma neoclássico não deveria ficar restrita, seja à crítica da teoria da função de produção neoclássica, como está na coletânea organizada por Oscar Braun (Braun, 1973); seja à crítica ao problema da transformação dos valores em preços de produção, como está enfatizado na obra de Ian Steedman (Steedman, 1985).

Para Celso Furtado, a decisiva contribuição de Sraffa foi abrir caminho para a retomada de uma teoria da acumulação de capital em escala global, 
à luz da transnacionalização do capitalismo e da complexificação das relações geopolíticas internacionais. Nesse sentido, Celso Furtado foi quem, entre os economistas da segunda metade do século XX, mais longe e criativamente se colocou uma efetiva reconstituição da economia política do capitalismo contemporâneo.

Mais ousado, se fizer sentido a comparação, é o livro de Celso Furtado, de 1979, Criatividade e dependência na civilização industrial, que classificou como "antiacadêmico" e que impressiona pela ousadia segura com que tenta apreender a sociedade contemporânea. No prefácio que escreveu para o livro, Celso Furtado se vê, perplexo, tentando iluminar uma realidade a cada momento mais complexa. Esse esforço intelectual que ele empreendeu recorrendo, de novo, à metáfora das sombras, com as quais vai dialogar em seu caminhar ensaístico, tendo como figura consular Jean Jacques Rousseau e seu "vagabundear intelectual". Logo depois de mencionar Rousseau, Celso Furtado invoca outra metáfora, a da música serial, em que são excluídas as tônicas e dominantes, para permitir que a massa sonora seja explorada em todas as direções (...) "É com este estado de espírito que se deve ler o que se segue: nem tônica, nem dominante: de qualquer ponto todo o horizonte deve descortinar-se." (Furtado, 2008, p. 34).

Em Criatividade e dependência na civilização industrial, Celso Furtado se colocou num lugar raro entre os intelectuais de sua época. Numa era de valorização da especialização e de simétrica suspeita das viradas gerais, do ensaísmo, a ousadia do livro de Celso Furtado está apoiada numa longa e reconhecida carreira como pesquisador seguro de suas fontes e métodos, e, sobretudo, que nunca dependeu de beneplácito corporativo ou promocional, que nunca se rendeu aos modismos, aos oportunismos. Mesmo assim, havia o risco, o risco de chocar mentalidades rotineiras, a mediocridade consagrada. Quantos intelectuais contemporâneos de Celso Furtado tentaram algo equivalente? Não se perca de vista que o livro em tela foi publicado em 1979, antes que episódios decisivos do nosso tempo tivessem se dado, em particular, a desaparição da União Soviética, a globalização globalitária e a expansão do poderio da China. Se essas questões forem colocadas em pauta, livros como os de Robert Kurz, O colapso da modernização, de 1991, O longo século XXI, de Giovanni Arrighi, de 1994, A era dos extremos, de Eric Hobsbawm, de 1994; O novo espírito do capitalismo, de Luc Boltanski e Ève Chiapello, de 1999, teriam que ser mencionados porque tentativas de grandes viradas sobre o mundo contemporâneo. 
O analisado por Celso Furtado em seu livro diz respeito ao capitalismo, da era imperialista até o final dos anos de 1970, ou seja, cem anos de história do capitalismo. Definido esse período histórico, o livro de Celso Furtado tem paralelo com o livro do grande historiador britânico, Geoffrey Barraclough, de 1964, Uma introdução à história contemporânea (Barraclough, [s.d.]). Uma comparação entre os dois revelará, é claro, importantes diferenças, de ênfases, de motivações, de formações, de vieses, mas, certamente, também revelará importantes convergências, sobretudo na maneira abrangente e transdisciplinar com que o tema, o mundo contemporâneo, foi tratado pelos dois autores. Os dois livros têm oito capítulos. A estruturação do livro de Barraclough é algo mais convencional que a do livro de Celso Furtado, que buscou maior integração entre as questões consideradas no livro. Os capítulos do livro de Barraclough são: 1) Natureza da história. Mudança estrutural e diferença qualitativa; 2) $\bigcirc$ impacto do progresso técnico, científico. Industrialização e imperialismo como catalisadores de um novo mundo; 3) Uma Europa menor. O significado do fator demográfico; 4) Do equilíbrio europeu de poder à era da política mundial. Transformações no ambiente das relações internacionais; 5) Do individualismo à democracia das massas. Organização política na sociedade tecnológica; 6) A revolta contra o Ocidente. A reação da Ásia e da África à hegemonia europeia; 7) $\bigcirc$ desafio ideológico. $\bigcirc$ impacto da teoria comunista e do exemplo soviético; 8) Arte e literatura no mundo contemporâneo. A mudança nas atividades humanas (Barraclough, [s.d.]).

A estrutura do livro de Celso Furtado buscou maior articulação no tratamento da matéria. Seus capítulos são mais abrangentes: 1) Poder e espaço numa economia que se globaliza; 2) Emergência e difusão da civilização industrial I; 3) Emergência e difusão da civilização industrial II; 4) Da ideologia do progresso à do desenvolvimento; 5) Acumulação e criatividade; 6) Dependência num mundo unificado; 7) Ensaio de visão retrospectiva; 8) Em busca de uma visão global (Furtado, 2008).

Em texto que abre Criatividade e dependência na civilização industrial Alfredo Bosi diz, em síntese feliz do livro: "Nas páginas finais ele alça voo na direção de um horizonte de pensamento que dialoga com diversas correntes filosóficas, estéticas e políticas, tendo por fio condutor um só valor, a criação de uma sociedade em que a potencialidade do indivíduo e do seu grupo se atualizem livremente." (Bosi, 2008, p. 30). Pensador radicalmente antiautoritário, Celso Furtado atualiza a aposta na construção de uma 
sociedade plenamente emancipada, isto é, da liberdade, da igualdade, da alteridade e da sustentabilidade.

\section{Referências}

BARRACLOUGH, Geoffrey. Introdução à história contemporânea. Trad. port. São Paulo: Círculo do Livro, [s.d.].

BOSI, Alfredo. Celso Furtado: rumo a uma visão holística. In: FURTADO, Celso. Criatividade e dependência na civilização industrial. Edição Definitiva. São Paulo: Companhia das Letras, 2008.

BRAUN, Oscar (Org.). Teoria del capital y la distribución. Trad. esp. Buenos Aires: Editorial Tiempo Contemporaneo, 1973.

COHN, Gabriel. Crítica e resignação. São Paulo: T. A. Queiroz, Editor, 1979.

FURTADO, Celso. Prefácio à nova economia política. Rio de Janeiro: Paz e Terra, 1976.

FURTADO, Celso. O mito do desenvolvimento econômico. 6. ed. Rio de Janeiro: Paz e Terra, 1983.

FURTADO, Celso. Cultura e desenvolvimento em época de crise. 2. ed. Rio de Janeiro: Paz e Terra, 1984.

FURTADO, Celso. Transformação e crise na economia mundial. Rio de Janeiro: Paz e Terra, 1987.

FURTADO, Celso. Criatividade e dependência na civilização industrial. São Paulo: Companhia das Letras, 2008.

HOLANDA, Sérgio Buarque de. Visão do paraíso. 2. ed. São Paulo: Companhia Editora Nacional, 1969.

HOLANDA, Sérgio Buarque de. O atual e o inatual na obra de Leopold Von Ranke. Revista de História, São Paulo, ano XXV, v. L, n. 100, out.-dez. 1974.

MARX, Karl. Para a crítica da economia política. Trad. port. São Paulo: Editora Abril, 1974. (Os Pensadores, Marx).

MERQUIOR, José Guilherme. L'esthétique de Lévi-Strauss. Press Universitaires de France, Croisées, 1977.

STEEDMAN, Ian. Marx, Sraffa y el problema de la transformación. Trad. esp. México: Fondo de Cultura Económica, 1985.

\section{Sobre o autor}

João Antônio de Paula-jpaula@cedeplar.ufmg.br

Centro de Desenvolvimento e Planejamento Regional, Universidade Federal de Minas Gerais, Belo Horizonte, Minas

Gerais, Brasil.

ORCID: https://orcid.org/0000-0002-5449-8671. 